\title{
Present Social Awareness and Economic Condition of Nomadic Bede Community at Narayanganj District in Bangladesh
}

\author{
Raf-Ana-Rabbi Shawon ${ }^{1, *}$, Mahbub-E-Rabbi ${ }^{2}$ \\ ${ }^{1}$ Department of Sociology, National University, Bangladesh \\ ${ }^{2}$ Department of Economics, Government Adamjee Nagar MW College, Bangladesh \\ *Corresponding author: rafana.shawon@gmail.com
}

\begin{abstract}
The Bedes were the nomadic people lived scattered and travelled throughout Bangladesh via rivers with a cluster form. The study was conducted in Naraynganj district during the time period from January, 2014 to August, 2014. About 650 bede peoples (Male 278, female 370 and hijra 2) data were collected randomly from various places of Narayangan district like langolbond, Mugrapara, Katchpur, Gulakandail, Kanchan with a prescribed preform questionnaire format. With a view to before finalize the study, the most important basic information were observed carefully within the community and various features of their social and economic data were collected. From the study, it was assumed that the Bede community severely deprived from all types of basic needs of living both social and economic. The most significant constraints were poverty, illiteracy, premature marriage and lack of consciousness about family planning. The social acceptance was uncommon due to their living style, very tough traditional and ritual bindings to make relationship with the other out peoples. They mostly lived under the poverty line. They passed their every day with untold sorrow and sufferings. Due to illiteracy, they were not engaged with officials and others sophisticated jobs. They were deviated from the mainstream of the country economics and development. It was a preliminary work. Further studies will necessary for revealed the unseen scenario of their sorrowful life and find out the solution of major constraints. Its high time to uncover the superstitions of their community and strongly recommended to the Government and others NGO's to introduce one stop service programs for developing the bede community both socially and economically.
\end{abstract}

Keywords: Bede, Khupri, Narayanganj, Nomadic, Shinga, Ther

Cite This Article: Raf-Ana-Rabbi Shawon, and Mahbub-E-Rabbi, "Present Social Awareness and Economic Condition of Nomadic Bede Community at Narayanganj District in Bangladesh.” American Journal of Rural Development, vol. 5, no. 4 (2017): 106-109. doi: 10.12691/ajrd-5-4-3.

\section{Introduction}

Bangladesh is one of the densely populated country of the world of about 168.95 million of peoples containing nearly 0.5 million of nomadic Bede people lives scatteredly in different parts of the country [1]. Banglapedia mentioned them as descendants of 'Montong' tribe of Myanmar. Bedes are the community belonging mainly to the ethnic Mong-Tong (Mongta) of Arakan, who in1638, accompanied the fugitive king of Arakan, Bellal raja, and later settled in Bikrampur and Munsiganj area near Dhaka. Later, the Bedes spread out to the remote areas of Bengal and Assam. Mangta people were popularly called 'Bede' after the Bangla word Baidda meaning 'village doctor'. Bede, the nomadic community in Bangladesh lives a free life under the free sky which is their custom from an unnoted time [2]. They are an ethnic group of Bangladesh. They mostly live in a nomadic life, moving from place to place to earn for living. Most of the bede community moves from one place to another for searching a suitable places for living and income especially during the rainy season when there is abundant rainfall and the rivers are rising with huge water, they live on boats as a tradition of themselves and travel to various places of Bangladesh plying their trade.

About $98 \%$ bede lives below the poverty line and 95\% are illiterate [3]. Since most Bede children travel with their parents and they change addresses very frequently due to their plying of their trades at various places, the children are unable to attend school. Most of the children also are from a young age asked by their parents to help in the household chores and trade. Though they had no right of votes till 2008, they have got the voting rights after 2008. Most of them speak in Bengali and majority of them are Muslim. Besides they also practice Hinduism, shamanism and animism. They don't take any kind of formal education due to their mobile life style (living in one place maximum 1-2 months). Due to very weak economic condition bedes are to depend mostly on traditional ethno-medicine practice, catching snakes, snake-selling, snake-charming, treating snake-bitten patients jharfuk, spiritual healing, shinga, magic-showing and advising on preventive measure to adopt to keep snake away from entering homesteads. They also sell 
various items like bangles and trinkets, cooking utensils, jewelry, spices etc [4].

There are huge numbers of bede peoples are living within Sonargaon and Rupganj Upazilla of Narayanganj district of Bangladesh since 2010. It's very rear for nomadic community being lived in a one place for a long time. Very little scientific research had been published on bede community. But no scientific research had been found about bede community lives in Narayanganj yet. That's why the authors showed the greatest interest to do her basic research about the present social awareness and economic condition of bede community lives in Narayanganj district Bangladesh for their appropriate description.

\section{Materials and Methods}

\subsection{Study Area}

Narayanganj is a district in central Bangladesh, part of the Dhaka Division. It is located in the bank of Shytolkha and Meghna river. Its adjuncts with is capital city of Dhaka. Narayanganj is one of the oldest industrial District of Bangladesh. It is nicknamed the Dundee of Bangladesh due to the presence of many jute mills. The study area Sonargaon and Rupganj upazilla is very popular for industries, processing plants, Jute mills, garments and textile business [5]. As a result, the bede community had been chosen these areas for their easy communication via river and best places as a source of income.

\subsection{Sampling Pattern}

The study was conducted in Naraynganj district during the time period from January, 2014 to August, 2014. About 650 bede peoples (Male 278, female 370 and hijra 2) data were collected randomly from various places of Narayangan district like langolbond, Mugrapara, Katchpur, Gulakandail, Kanchan with a prescribed format. The data were collected directly face to face interview from the bede peoples with the help of pre-form questionnaire. With a view to reach to the research goal, adopted the most important basic information for collection of data and then observed various features of their daily lives.

\subsection{Statistical Analysis}

All the collected data were put into excel spread sheet and analyzed by Statistical Package for Social Science (SPSS) version 20.0 programme.

\section{Results and Discussions}

All the socio-economic data of bede community were shown in the Table 1 . The authors were very astonished when they observed the actual scenario of the bede community of these area. They had bear an identity of a sub-tribe headed by a particular oldest person called 'Sardar'. Sardar took the decisions about the good or bad of the community, trade routes, area of operation for every group, marriage couple, and new destination. He executed penalty for the community person who violated their own norms and culture. The present findings were agreed with the findings of Hossain et al., [6]. He described that Sarder was the main leader of their community and decided everything. The Bedeys have their own language called "Thet or Ther", similar with the language of Arakanese. They used it within community. Bedeys were in these area were lived under the poverty line. Most of the important facilities were absent in their household. Most of the families were in nuclear type (87\%), very few remain in joint family (13\%). A total number 650 bede peoples (Male 278, female 370 and hijra 2) data were collected where male, female and other sex were $42.90 \%, 57 \%$ and $0.1 \%$ respectively. Average age range of the peoples were $0-10,11-20,21-30,31-50$ and above 50 years found $18 \%$, $17 \%, 27 \%, 31 \%$ and $9 \%$ respectively. $21-30$ and $31-50$ years age groups were the most active groups in terms of occupation, general knowledge and ability to work actively. The older persons, above 50 years group particularly among the mal-vaidyas and the ojhas were more knowledgeable, thoughtful and role maker as to their ethno medicinal practices, which have been practiced from time immemorial. This study was agreed with the findings of Hossain et al., [6]. The proportion of the birth rate was very high. Every family had minimum 1-3 Childs at least. The percent of 1-3, 4-5 and above 6 child's were found to be $38 \%, 47 \%$ and $15 \%$ respectively. Their population was growing day by day but they did not know how could manage the food and also the shelter for their childs to live. Not only poverty plays a drastic constraint for getting education of the children but also their nomadic lifestyle restricts their children not to get admitted into the school. But todays Bangladesh government and few NGO's was coming forward to disseminate education to the bedes children. Although they were mostly not interested to educate their childs. That's why most of the peoples were illiterate (58\%) and moderate percentage were only completed the primary education (40\%). Very few percentages were going to secondary education (2\%) but not completed. This was because they were very poor, adults wanted their boys or girls to work with others or individually as for income. They could not imagine about the higher education. Hossan et al., [7] found that among the literate people, only $2.7 \%$ passed SSC, HSC and rarely above, $18.1 \%$ read from Class $\mathrm{V}$ to $\mathrm{X}$ and the rest were just literate. In case of marriage system, they hardly maintained their own religious norms and ritual facts. The average age of the marriage was 12-15 years. The girls when reach in 12 years mostly sited for marriage by their family decision. Most of the boys were married in the age of 15-17 years. After marriage, the husband went to the wife's house to live permanently. The wife had taken a vow that she will take care of her husband and the children until death. The bede peoples were practiced premature marriage as a tradition of their own.

From the present study it was revaeled that the bede peoples were mostly lived with their families in khupri, boat, ekchala or in the tents and the percentage was $76 \%$, $10 \%$ and $14 \%$ respectively. Though we know that they were lived in boat mostly but in these areas they didn't. Because of the geographical region variation and the availability of the unused land and long time they have lived there. Before buildup their house in a new area, the 
sardar took the permission of the local political leader or Matubbar. Since their khupri was made with polythene and bamboo that was unable to adapt natural calamities. The bede population was increasing highly day by day due to lack adopt about family planning. The male could not interest to maintain the family in small. But their female was very keen to use pill (69\%) named Sukhi supplied free from the government for control of unwanted birth. Few woman was took ligation (15\%), Norplant (11\%). Most of the Bede peoples were lived below poverty line. Female was the backbone of their income source. Few male was going 2-3 days in a week for income but majority remain in house without any work. The utmost common profession was to practice ethno-medicines (18\%), snake charming (17\%), Shinga (33\%), selling Bangles and trinkets (5\%), Home Utensils (7\%) among the nearest rural women, working on a Confectionary shop (1\%), buildup a Tea Stall (5\%) and selling tea on a road side, riding Rickshaw (2\%) and practiced Jharfuk (12\%) including different kinds of wild creepers, leaves and roots selling. Their other profession includes curing carious teeth by using special plant extract. Prashant et al., [8] who described that leaves of Azadirachta indica, a plant known to have anti-microbial properties against four organisms causing dental caries. The interesting method of curing sick peoples, the bede woman used 'shinga', made from buffalo or cattle horn, was a hollow sucker used to draw blood from a sick patient waist for withdrawn to cure the sickness where a cut was made and the Bede woman then sucks heavily from the sawed-off tip of the horn, thus sucking out blood [7]. Their daily income was very low on an average 200-300 BDT per day. Very few time, they earned above 500 BDT per day. The Bedes were mostly Muslims but they believed in a number of gods and goddesses, mainly snake goddess, called "Monsha". They were passed their leisure time showing movie, natok on TV (40\%), went to nearest cinema hall for saw the latest cinema (29\%), using android mobile phone (26\%) for hearing song and saw video movie on it. The few were fond of $\mathrm{f}$ play games (4\%) like football, Cricket, danguli and practicing tas for their recreation and passing their leisure time. Hossan et al., [7] described that bedes had limited scope for recreation and they used radio \& record player (24\%), TV, radio \& record player (81\%) for their recreation. About $31 \%$ do not have any means of recreation and no one has internet facilities.

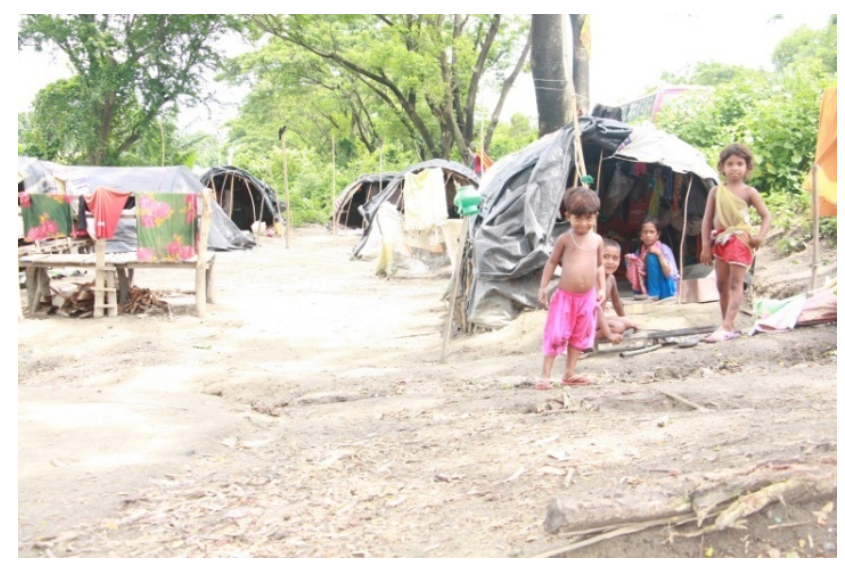

Figure 1. The housing system of the bede community
Table 1. Socio-economic information of bede community in Narayanganj

\begin{tabular}{|c|c|c|}
\hline \multicolumn{2}{|c|}{ Traits } & \multirow{2}{*}{$\begin{array}{r}\text { Percentage } \\
42.90 \%\end{array}$} \\
\hline \multirow{3}{*}{ Sex } & Male & \\
\hline & Female & $57 \%$ \\
\hline & Others & $0.1 \%$ \\
\hline \multirow{5}{*}{ Age (years) } & $0-10$ & $18 \%$ \\
\hline & $11-20$ & $17 \%$ \\
\hline & $21-30$ & $27 \%$ \\
\hline & $31-50$ & $31 \%$ \\
\hline & Above 50 & $9 \%$ \\
\hline \multirow{2}{*}{ Family type } & Nuclear & $87 \%$ \\
\hline & Joint & $13 \%$ \\
\hline \multirow{3}{*}{ Family members number } & $1-3$ & $38 \%$ \\
\hline & $4-5$ & $47 \%$ \\
\hline & above 6 & $15 \%$ \\
\hline \multirow{4}{*}{ Education } & Illiterate & $58 \%$ \\
\hline & Primary & $40 \%$ \\
\hline & Secondary & $2 \%$ \\
\hline & College/university & $0.0 \%$ \\
\hline \multirow{4}{*}{ Marriage age (years) } & $12-15$ & $56 \%$ \\
\hline & $16-20$ & $42 \%$ \\
\hline & $21-25$ & $1.9 \%$ \\
\hline & Above 25 & $0.1 \%$ \\
\hline \multirow{3}{*}{ House type } & Khupri & $76 \%$ \\
\hline & Boat & $10 \%$ \\
\hline & Tent and ekchala & $14 \%$ \\
\hline \multirow{6}{*}{ Family Planning } & Condom (male) & $1 \%$ \\
\hline & Pill (Female) & $69 \%$ \\
\hline & Norplant(Female) & $11 \%$ \\
\hline & Ligation (female) & $15 \%$ \\
\hline & Vasectomy (male) & $1 \%$ \\
\hline & others & $3 \%$ \\
\hline \multirow{3}{*}{ Income person } & Male & $28 \%$ \\
\hline & Female & $71 \%$ \\
\hline & Others & $1 \%$ \\
\hline \multirow{10}{*}{ Income source } & Snake Charming & $17 \%$ \\
\hline & Jharfuk & $12 \%$ \\
\hline & Ethno-medicine & $18 \%$ \\
\hline & Shinga & $33 \%$ \\
\hline & Bangles, trinkets & $5 \%$ \\
\hline & Home Utensils & $7 \%$ \\
\hline & Confectionary & $1 \%$ \\
\hline & Tea Stall & $5 \%$ \\
\hline & Rickshaw polar & $2 \%$ \\
\hline & Govt. Service & $0 \%$ \\
\hline \multirow{5}{*}{ Recreation Source } & TV & $40 \%$ \\
\hline & Radio & $1 \%$ \\
\hline & Cinema & $29 \%$ \\
\hline & Mobile & $26 \%$ \\
\hline & Play Games & $4 \%$ \\
\hline
\end{tabular}




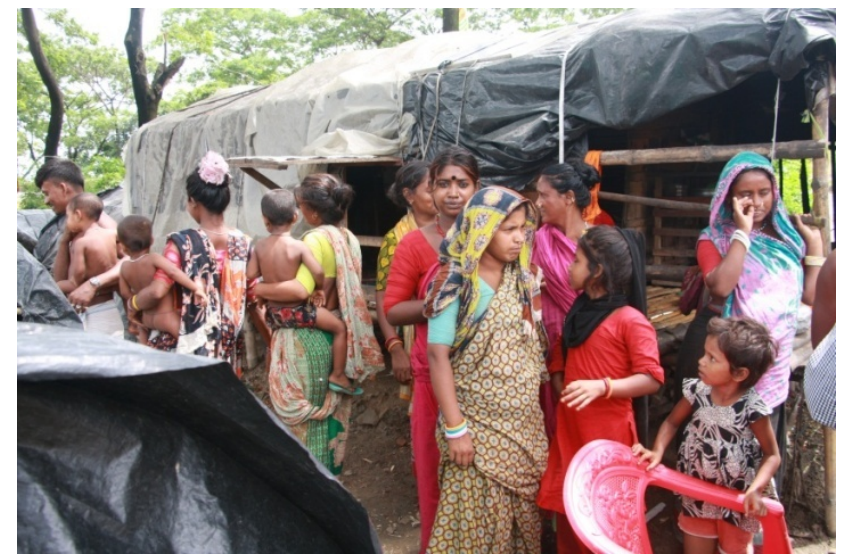

Figure 2. The bede peoples were gossiping with each other in front of their Khupri house

\section{Conclusion}

From the study it was very clear that the Bede community severely lack from all types of basic needs of life both social and economic. The most significant constraints were poverty, absent of mass education, early marriage and uncontrolled birth of children. They tried to shift from their own income pattern to the newly described occupation. But they were struggling to save their own customs and culture which they were brought thousand years ago from their pioneers until date. Government and NGO's were come forward to establish them in the main stream of the society and our economic system. But facilities were very trace. It was a preliminary work. Further studies will necessary for revealed the unseen scenario of their sorrowful life and find out the solution of major constraints. They must be introduced in country mainstream economy and development. The vision of the Govt. will be ruined if they were untreated and underdeveloped. The Govt. and NGO's must be introduced both technical and general education to all bede peoples, adopt efficient peoples to various govt. jobs, provide SME loan and enhance facility to train up the female for making different types of handicraft, poultry and large animal farming, gardening and vegetation. Strictly followed the marriage law and registration system. The govt. should introduce one stop service programs for developed the bede community in the field of socio-economy in Bangladesh.

\section{Acknowledgements}

The authors were very much grateful to the bede community lived in Sonargaon and Rupganj, for providing all sorts of necessary and helpful data for this study. It was a partial research work of the first author during her undergraduate final report writing.

\section{Conflict Interest}

The authors have no intension to compete any other regarding this study. All authors were given optimum contribution to prepare this manuscript successfully.

\section{References}

[1] Beurden, J.V. (2007). A new research culture for the marginalized in Bangladesh, JIS news letter, Vol. 43.

[2] Dalton, E.T. (1978). Tribal History of Eastern India. New Delhi: Cosmo Publications.

[3] Maksud, A.K.M. (2006). Participatory actions research for human development for nomadic bede community, Grambangla Unnayan committee and research initiatives, Dhaka, Bangladesh.

[4] Arefeen, H.K.S. (1992). Sub-culture: Society of Bangladesh. Samaj Nirikhan, Vol.46. Samaj Nirikhan Kendra, Dhaka.

[5] Bhuiyan, M.H. (2012). "Narayanganj District". In Islam, Sirajul; Jamal, Ahmed A. Banglapedia: National Encyclopedia of Bangladesh (Second ed.). Asiatic Society of Bangladesh.

[6] Hossain, M.T., Miajee, E.U., Khatun, M.A., and Rahmatullah, M. (2010). A Preliminary Study of the Health Management Practices of the Bede Community of Savar, Bangladesh and some of their Ethnomedicinal Formulations. American-Eurasian Journal of Sustainable Agriculture, 4(2): 136-146.

[7] Hossan, M.S., Khan, A.H.M., Bari, S., Jahan, R. and Rahmatullah, M. (2009). Ethnobotanical survey of the Tripura tribe of Bangladesh. American Eurasian Journal of Sustainable Agriculture, 3(2): 253-261.

[8] Prashant, G.M., Chandu, G.N., Murulikrishna. K.S. and Shafiulla, M.D. (2007). The effect of mango and neem extract on four organisms causing dental caries: Streptococcus mutans, Streptococcus salivavius, Streptococcus mitis, and Streptococcus sanguis: an in vitro study. Indian Journal of Dental Research, 18: 148-151.

[9] Hossan, M.S., Hanif, A., Agarwala, B., Sarwar, M.S., Karim, M., Rahman, M.T., Jahan, R. and Rahmatullah, M. (2010). Traditional use of medicinal plants in Bangladesh to treat urinary tract infections and sexually transmitted diseases. Ethnobotany Research and Applications, 8: 61-74.

[10] World Population Review 2016. http://worldpopulationreview.com/countries/ bangle desh-population. 